DR. TRACY FRECH (Orcid ID : 0000-0002-5472-3840)

DR. SABRINA HOA (Orcid ID : 0000-0002-9466-5729)

\title{
Article type Brief Report \\ a \\ GENERATION OF A CORE SET OF ITEMS TO DEVELOP CLASSIFICATION CRITERIA FOR SCLERODERMA RENAL CRISIS USING CONSENSUS METHODOLOGY
}

Emily-Ann Butler, BS (Hons) ${ }^{1}$; Murray Baron, MD², Agnes B. Fogo, MD; Tracy Frech, MD MS; Cybele Ghossein, $\mathrm{MD}^{6}$; Eric Hachulla, MD${ }^{7}$; Sabrina Hoa, MD ${ }^{3,8}$; Sindhu R. Johnson, MD PhD Dinesh Khanna, MD MS ${ }^{10}$; Luc Mouthon, MD $\mathrm{PhD}^{11}$; Mandana Nikpour, MD PhD ${ }^{12}$; Susanna Proudman, MB BS (Hons) ${ }^{13}$; Virginia Steen, MD ${ }^{14}$; Edward Stern, MBBS ${ }^{15}$; John Varga, MD ${ }^{6}$; Christopher Denton, PhD FRCP15; Marie Hudson, MD MPH ${ }^{2,3,8}$; Scleroderma Clinical Trials Consortium Scleroderma Renal Crisis Working Group*

Institutional affiliations: ${ }^{1}$ Dalhousie University, Halifax, Canada; ${ }^{2}$ Jewish General Hospital, Montreal, Canada; ${ }^{3}$ McGill University, Montreal, Canada; ${ }^{4}$ Vanderbilt University Medical Center, Nashville, USA; ${ }^{5}$ University of Utah, Salt Lake City, USA; ${ }^{6}$ Northwestern University - Feinberg School of Medicine, Chicago, USA; ${ }^{7}$ University of Lille - Hôpital Claude Huriez, Lille, France; ${ }^{8}$ Lady Davis Institute, Montreal, Canada; ${ }^{9}$ Toronto Scleroderma Program, Division of Rheumatology, Department of Medicine, Toronto Western Hospital, Mount Sinai Hospital, University of Toronto, Toronto, Ontario, Canada; ${ }^{10}$ University of Michigan, Ann Arbor, USA; ${ }^{11}$ Department of Internal Medicine, Cochin Hospital, Paris-Descartes University, Paris, France; ${ }^{12}$ University of Melbourne at St. Vincent's Hospital, Victoria, Australia; ${ }^{13}$ Royal Adelaide Hospital and University of Adelaide, Adelaide, Australia; ${ }^{14}$ Georgetown University, Washington DC, USA; ${ }^{15}$ Royal Free Hospital, London, UK .

This is the author manuscript accepted for publication and has undergone full peer review but has not been through the copyediting, typesetting, pagination and proofreading process, which may lead to differences between this version and the Version of Record. Please cite this article as doi: $\underline{10.1002 / \operatorname{art} .40809}$

This article is protected by copyright. All rights reserved 


\section{*Investigators of the Scleroderma Clinical Trials Consortium Scleroderma Renal Crisis Working}

Group: April Barnado (Vanderbilt University Medical Center), Murray Baron (Jewish General Hospital), Elana J. Bernstein (Columbia University Medical Center), Francesco Boin (University of California San Francisco), Yolanda Braun-Moscovici (Rheumatology Institute, Rambam Health Care Campus, Rappaport Faculty of Medicine, Technion, Haifa, Israel), Flavia V. Castelino, M.D.

(Massachusetts General Hospital, Harvard Medical School), Luis J. Catoggio (Hospital Italiano de Buenos Aires), Mareo Matucci-Cerinic (University of Florence), Lorinda Chung (Palo Alto VA Health Care System, Stanford University), Philip Clements (University of California, Los Angeles), Mary Ellen Csuka (Medical College of Wisconsin), Ellen De Langhe (University Hospital Leuven, Rheumatology Department), Christopher Denton (Royal Free Hospital), Jörg Distler (Friedrich-Alexander-University, Erlangen-Nürnberg), Oliver Distler (University Hospital Zurich), Dominique Claire Farge (AP-HP, St

Louis Hospital, Université Denis Diderot, France), Aryeh Fischer (University of Colorado), Agnes Fogo (Vanderbilt University), Tracy Frech (University of Utah, Salt Lake Veterans Affairs Medical Center), Armando Gabrielli (Università Politecnica delle Marche), Cybele Ghossein (Northwestern University Feinberg School of Medicine), Eric Hachulla (National Referral Centre for Rare Systemic Auto-immune Diseases North and North-West of France, University of Lille, Huriez Hospital), Minoru Hasegawa (University of Fukui), Samina Hayat (Louisiana State University), Ariane Herrick (University of Manchester), Roger Hesselstrand (Lund University Hospital), Sabrina Hoa (McGill University), Vivien Hsu (Rutgers-RWJ Medical School), Marie Hudson (McGill University), Michael Hughes (University of Manchester), Nicolas Hunzelmann (University of Cologne), Laura Hummers (Johns Hopkins University), Florenzo Iannone (University of Bari), Francesca Ingegnoli (Università degli Studi di Milano), Soren Jacobsen (Rigshospitalet), Sindhu Johnson (University of Toronto), Yasushi Kawaguchi (Tokyo Women's Medical University), Dinesh Khanna (University of Michigan), Martial Koenig (University of Montreal), Masataka Kuwana (Nippon Medical School), Jan Lenaerts (University Hospital Leuven, Rheumatology Department), Thierry Martin (National referral center for systemic autoimmune diseases, Strasbourg University Hospital), Maureen D. Mayes (University of Texas McGovern Medical School, Houston), Zsuzsanna McMahan (Johns Hopkins University), Thomas Medsger (University of Pittsburgh), Peter Merkel (University of Pennsylvania), Sonali Narain (Northwell Health), Mandana Nikpour (University of Melbourne, St. Vincent's Hospital), Voon Ong (University College London), John D. Pauling (Royal National Hospital for Rheumatic Diseases , University of Bath), Janet Pope (University of Western Ontario, St. Joseph's Health Care), Susanna 
Proudman (Royal Adelaide Hospital, University of Adelaide), Carlos de la Puente Bujidos (Hospital Ramón y Cajal), Maureen Rischmueller (Queen Elizabeth Hospital, University of Adelaide), Tatiana Sofía Rodríguez-Reyna (Instituto Nacional de Ciencias Médicas y Nutrición Salvador Zubirán), Joanne Sahhar (Monash Health, Monash University), Lesley Ann Saketkoo (New Orleans Scleroderma and Sarcoidosis Patient Care and Research Center, Tulane University Lung Center), Jean-Luc Senécal (University of Montreal Scleroderma Research Chair, Centre Hospitalier de l'Université de Montréal), Ankoor Shah (Duke University), Ami A. Shah (Johns Hopkins University), Walter Alberto SifuentesGiraldo (Ramón y Cajal University Hospital), Richard Silver (Medical University of South Carolina), Virginia Steen (Georgetown University Medical Center), Edward Stern (University College London), Wendy Stevens-(St. Vincent's Hospital), Evelyn Sutton (Dalhousie University), Vivek Thakkar (Macquarie University), Gabriele Valentini (Università degli Studi della Campania), Jeska de VriesBouwstra (Leiden University), Madelon Vonk (Radboud University), Ulrich A. Walker (Basel University Hospital)

Funding: This study was funded by a grant from the Scleroderma Clinical Trials Consortium. Dr Hudson is funded as a Clinician Scientist by the Fonds de Recherche du Québec - Santé. Dr Stern was supported by MRC grant MR/K015230/1. The funding sources had no role in the design and conduct of the study; colleetion, management, analysis, and interpretation of the data; preparation, review, or approval of the manuscript; and decision to submit the manuscript for publication.

Corresponding author: Marie Hudson, Jewish General Hospital, 3755 Côte Ste Catherine Road, Montreal, Quebec, Canada, H3T 1E4; tel. (514) 340-8222 ext. 23476; E-mail: marie.hudson@mcgill.ca

\section{Word count: 2494}

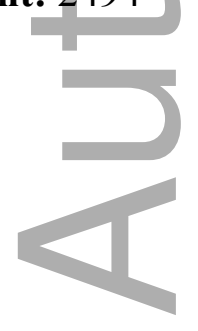

This article is protected by copyright. All rights reserved 


\section{$\underline{\text { Abstract }}$}

Background: This project was undertaken to generate a core set of items to develop classification criteria for scleroderma renal crisis (SRC) using consensus methodology.

Methods: An international, multidisciplinary panel of experts was invited to participate in a 3-round Delphi exercise developed using a survey based on items identified by a scoping review. In Round 1, participants were asked to identify omissions and clarify ambiguities regarding the items in the survey. In Round 2, participants were asked to rate the validity and feasibility of the items using Likert-type scales ranging from 1-9 (1= very invalid/unfeasible, $5=$ uncertain, $9=$ very valid/feasible). In Round 3, participants reviewed the results and comments of Round 2, and were asked to provide final ratings. Items rated as highly valid and feasible (both median scores $\geq 7$ ) in Round 3 were selected as the provisional core set of items. A consensus meeting using nominal group technique (NGT) followed to further reduce the core set of items.

Results: Ninety-nine experts from 16 countries participated in the Delphi exercise. Of the 31 items in the survey, consensus was achieved on 13, including hypertension, renal insufficiency, proteinuria and hemolysis. Eleven experts took part in the NGT discussion, where consensus was achieved in 5 domains: blood pressure, acute kidney injury, microangiopathic hemolytic anemia, target organ dysfunction, and renal histopathology.

Conclusions: A core set of items that characterize SRC was identified using consensus methodology. This core set will be used in future data-driven phases of this project to develop classification criteria for SRC.

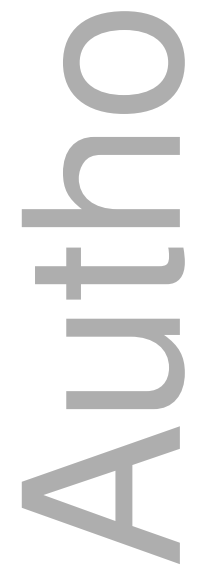

This article is protected by copyright. All rights reserved 


\section{$\underline{\text { Introduction }}$}

Scleroderma renal crisis (SRC) is a life-threatening complication of systemic sclerosis (SSc) (14). It is usually characterized by malignant hypertension and acute kidney injury (3). However, the clinical spectrum of SRC is broad, ranging from full-blown disease presenting as new onset accelerated arterial hypertension and rapidly progressive oliguric renal failure, to more modest elevations in blood pressure and renal dysfunction, and at times normotensive presentations. On the other hand, hypertension without uraemia, urinary abnormalities and/or mild uraemia attributable to other factors (e.g., concomitant comorbidities such as diabetes or exposure to nephrotoxic medications) are common in SSc $(4,5)$. These conditions should not be confused with SRC.

$\mathrm{SRC}$ is relatively rare, occurring in about $5 \%$ of all SSc patients (3). It is more common in patients with rapidly progressing diffuse cutaneous SSc (dcSSc) (11\%) as compared to patients with limited cutaneous SSc (lcSSc) (4\%) (6). SRC can be further sub-categorized into hypertensive or normotensive forms, representing approximately $90 \%$ and $10 \%$ of SRC cases, respectively $(7,8)$. Historically, SRC was the leading cause of death in SSc (9). However, with the advent of angiotensin converting enzyme (ACE) inhibitors, mortality rates have decreased significantly $(10,11)$. Nevertheless, one-year outcomes remain poor, with over $30 \%$ mortality and $25 \%$ of patients remaining dialysisdependent (12). There is an urgent need to undertake research to identify novel treatments and to improve outcomes of SRC.

In addition to heterogeneity and rarity, the absence of a gold standard and classification criteria are important challenges for research on SRC. To date, most studies of SRC have used ad hoc criteria that have varied considerably from study to study. In a scoping review of the literature, 40 original definitions of SRC, with significant heterogeneity among them, were identified (13). Only one study to date has partially validated criteria for SRC (12).

The Scleroderma Clinical Trials Consortium (SCTC) SRC Working Group was created to develop classification criteria for SRC. The objective of this phase of the study was to generate a core set of items to define SRC using consensus methodology. Future studies using data-driven methods will be required to develop and validate classification criteria for SRC. 


\section{$\underline{\text { Methods }}$}

A scoping review of the literature to identify items used to define SRC has been published (13). The results of this reyiew were used to inform this project, which consisted of two phases: 1) a modified online Delphi exercise to develop provisional consensus on a core set of items to define SRC and 2) a consensus meeting using nominal group technique (NGT) to further reduce the core set. Ethics approval for this project was obtained from the Jewish General Hospital Research Ethics Board, Montréal, Quebec, Canada(Protocol \# CODIM-MBM-17-104).

\section{Phase 1: Delphi}

A modified, online, 3-round Delphi exercise was conducted (14,15). Experts from the SCTC, European Scleroderma Trials and Research Group (EUSTAR), Canadian Scleroderma Research Group (CSRG) and Australian Scleroderma Interest Group (ASIG) were invited to participate. In addition, pathologists and nephrologists known through these organizations with interest in SRC were also invited to participate. Individuals interested in participating were asked to accept the invitation by return email. All individuals who accepted were then considered study participants, and thereby constituted the denominator for the participation rates.

The Delphi survey was developed and managed through the REDCap platform (Vanderbilt University, Nashville, Tennessee). In Round 1, consent to participate was obtained and demographic and personal information was collected on participants. Subsequently, Round 1 asked participants to consider the items identified in the scoping review and requested them to clarify ambiguities, identify omissions and provide comments. Items were modified accordingly.

In Round 2, participants were asked to rate the scientific validity, empirical validity and feasibility of the items using Likert-type scales ranging from 1-9 (1= very invalid/unfeasible, $5=$ uncertain, 9 = very valid/feasible) and to provide comments. Participants were provided links to full-text copies of the scoping review and all of the papers included therein. Scientific validity was defined as items supported by published literature and empirical validity as items supported by personal experience and knowledge of professional consensus. Feasibility was defined in terms of whether the item could be performed/tested in an easy or convenient matter.

In Round 3, the results of Round 2 were presented using summary statistics, including medians and interquartile ranges, and bar graphs. Participants were also shown their answers and anonymized 
comments from other participants from Round 2. The participants were then asked to provide their final rating on scientific validity, empirical validity and feasibility of the items.

Consensus was defined as items rated highly scientifically valid and feasible (both median scores $\geq 7$ ) in Round 3, and for which there was no disagreement, calculated using the RAND/UCLA Appropriateness Method formula. Disagreement exists when the inter-percentile range (IPR: difference between the $30^{\text {th }}$ and $70^{\text {th }}$ percentiles) is larger than the IPR adjusted for symmetry (IPRAS), calculated as follows:

\section{IPRAS $=2.35+[$ Asymmetry Index x 1.5]}

Derivation of the formula is shown in the RAND/UCLA Appropriateness Method handbook (16).

\section{Phase 2: NGT meeting}

The second phase of this study was to reduce the number of items and achieve consensus using NGT (17). International experts, including rheumatologists, internists and nephrologists, were invited to participate in a 2-hour face-to-face meeting held in November 2017 in San Diego (California, USA). Dr. Dinesh Khanna moderated the discussion based on expertise and previous experience in the fields of SRC and NGT techniques $(17,18)$. Each item from the Delphi was discussed in turn. Each panelist was invited to provide comments. At the end of the discussion, the panelists were asked to vote by a show of hands if the items should be included in the core set. A simple majority was required to include the item.

During the NGT meeting, it became clear that some items required content expertise beyond rheumatology, internal medicine and nephrology. Thus, some items were conditionally included, pending further review with content experts. Experts in hematology, neurology, ophthalmology, and cardiology were then contacted and asked to provide input and published evidence to define items in those domains.

A final list of core set items (and their definitions) was compiled and circulated among the participants of the NGT meeting for final approval.

\section{$\underline{\text { Results }}$}

\section{Phase 1: Delphi}

We contacted 216 people with an interest in SRC of which 99 agreed to participate in the modified online Delphi exercise. Of those, 77 (78\%), 60 (61\%) and 69 (70\%) participated in Rounds 1, 2 and 3, respectively, and 49 (49\%) completed all three rounds of the exercise. Participants were mainly rheumatologists $(86 \%)$ with some internists, nephrologists and pathologists. Most participants worked as 
clinicians for $>11$ years, with only a few having less than 10 years of experience $(13 \%)$. The majority of participants were from the United States (35\%) followed by Canada (11\%); 16 other countries were also represented.

A total of 31 items in 11 categories were included in the Delphi exercise. Of these, 13 items in 4 categories (hypertension, renal insufficiency, proteinuria and hemolysis) achieved consensus in Round 3 (median ratings $\geq 7$ on scientific validity and feasibility with no disagreement). Disagreement on feasibility was only present for hyper-reninemia. In any case, that item had not achieved consensus on feasibility either. Of note, all items that reached consensus in Round 2, also reached consensus in Round 3 with no additional items reaching consensus in Round 3. However, the IQR for the majority of items became smaller in Round 3, demonstrating growing consensus. The median ratings and IQR for each item for Rounds 2 and 3 are presented in Table 1.

\section{Phase 2: Nominal Group Technique meeting}

Seventeen international experts were invited to participate in a face-to-face NGT meeting. Six were not available. Thus, the panel consisted of 11 participants, 10 rheumatologists and 1 nephrologist, from the USA, Canada, United Kingdom, France, Netherlands and Australia. Prior to the NGT meeting, the 11 categories from the Delphi exercise were re-organized into 5 domains (hypertension, renal dysfunction [renal insufficiency, proteinuria, hematuria and hyper-reninemia], microangiopathic hemolytic anemia with thrombocytopenia, target organ dysfunction [encephalopathy, retinopathy and cardiac dysfunction] and renal histopathology). Prior to and at the meeting, it was agreed that items should be defined as much as possible according to evidence and/or international guidelines. Content experts in hematology, neurology, ophthalmology, and cardiology were contacted to provide input on definitions of items included in the core set.

The final core set of items and their definitions are presented in Table 2, and were approved by the NGT participants.

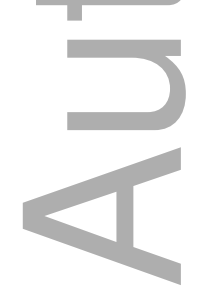

\section{$\underline{\text { Discussion }}$}


In this study, we generated a core set of items to classify SRC using consensus methodology. This core set includes 5 domains and 14 items. The definitions for each item were evidence-based or, in the absence of evidence, determined in consultation with content experts.

The progress made to date to develop classification criteria for SRC demonstrates the importance of using the best evidence available. A scoping review of the literature identified 40 heterogeneous definitions of SRC using more than 40 items with variable definitions (13). The Delphi exercise led to consensus on 13 of these items. However, the need to go beyond consensus in the rheumatology community and to get the input of content experts emerged as a critical factor at the NGT meeting. Thus, the input from content experts was sought to finalize the core set. Proteinuria is a perfect example of how this approach allowed the core set to evolve. Indeed, low-level proteinuria is common in SSc (4), dipstick and urine protein-to-creatinine ratio are not reliable in AKI, proteinuria is not part the Kidney Disease Improving Global Outcomes (KDIGO) definition of AKI (19), and proteinuria would compromise specificity of SRC criteria. Thus, despite the fact that there was consensus to include proteinuria in the core set after the Delphi exercise, this item was excluded after the NGT meeting and discussion with nephrologists.

A core set of variables to define SRC was proposed by experts in 2003 (7). It included items for systolic and diastolic blood pressure, serum creatinine, proteinuria, hematuria, microangiopathic hemolytic anemia and renal histopathology. These are known as the Ancona criteria for SRC. Our core set has similarities to the Ancona criteria in particular with respect to blood pressure. However, there are also notable differences in defining acute kidney injury (including the exclusion of proteinuria and hematuria). In addition, our core set includes target organ dysfunction and a detailed histopathological description of SRC.

In 2016, the UK Scleroderma Study Group proposed criteria for the diagnosis of SRC (20). The criteria were divided into categories: diagnostic criteria (essential) and supportive evidence (desirable) with blood pressure and AKI as the former, MAHAT, hypertensive retinopathy, hematuria, oliguria or anuria, renal biopsy consistent with SRC features and flash pulmonary edema as the latter. Discrepancies with our proposed criteria are found in the slightly modified cut-off values for blood pressure $(150 / 85 \mathrm{mmHg}$ versus $140 / 90 \mathrm{mmHg})$ and additionally, there is no noted rise in diastolic blood pressure, only $\geq 20 \mathrm{mmHg}$ for systolic blood pressure which is lower than $\geq 30 \mathrm{mmHg}$ proposed in this study. Further, the UK criteria included hematuria. Additionally, oliguria and flash pulmonary edema were proposed as stand-alone items whereas in our list, these items are grouped into the AKI and acute 
heart failure definitions, respectively. Our core set provides a more in depth detailed definition for each item, specifically for AKI, MAHAT and renal histopathology.

Only one study to date has attempted to validate the Ancona criteria and another slightly different set of criteria for SRC that included encephalopathy (12). In that study, a diagnosis of SRC confirmed by a study physician was used as the gold standard for SRC. Compared to the gold standard, the two sets of criteria identified 70/70 subjects with hypertensive, but only 2/5 subjects with normotensive SRC. We believe that our core set, which was developed using robust consensus methodology and evidence-based content, represents a significant advancement over these definitions. In addition, it defines target organ involvement and provides a detailed histopathological description to define the term "findings consistent with SRC".

This study has some limitations. First, only 99/216 experts invited to participate accepted and 77 (78\%), 60 (61\%) and 69 (70\%) of these participated in Rounds 1-3 of the Delphi, respectively. We cannot exclude some response bias. Part of the reason for the low response rates may have been that the Delphi exercise was conducted during the summer and early fall in the Northern hemisphere. Numerous out of office replies were returned. On the other hand, to mitigate this source of bias, reminder emails were sent to optimize participation rates and the final sample was still substantial and representative. Second, there are large gaps in knowledge on SRC. Hence, participants in the Delphi may have rated validity based more on empirical, rather than on scientific evidence. Nevertheless, we provided the Delphi participants with the scoping review and all of the original papers included therein in every Round for easy access to the available literature. Third, recruitment of participants with a broad range of expertise is critical to the success of a consensus-building exercise. Although there were a few specialists other than rheumatologists who participated in the Delphi, it became clear at the NGT meeting that content expertise in hematology, neurology, ophthalmology, and cardiology was lacking. We therefore recruited experts in all of these fields to help finalize the relevant items.

This study has substantial strengths. The emphasis on evidence and input from content experts ensured that the final core set had face and content validity. The geographic range of participants contributed to the generalizability of the results. There was important complementarity in the use of both a Delphi exercise and a semi-structured NGT consensus meeting. The Delphi provided a cost-effective approach to survey a larger sample of international experts working anonymously. The NGT meeting allowed for a time-efficient, face-to-face discussion of a smaller sample of experts led by an experienced moderator.

This article is protected by copyright. All rights reserved 


\section{Conclusion and future steps}

In conclusion, using consensus methodology, we generated a core set of items, and the definition of those items, to be used in the development of classification criteria for SRC. To determine if and how these items should be incorporated into classification criteria for SRC, two future phases of this research project are now in planning. The first, modeled on the International Scleroderma Renal Crisis Survey (12), will be to recruit an inception SRC cohort and collect the items in the core set. A comparison cohort consisting of subjects with conditions that mimic SRC will also be assembled. These data will be used to develop and validate classification criteria for SRC. The second will be a forced choice study using multi-criteria decision analysis methods to assign weights to the items in the criteria and to set probability values for definite, probable and possible SRC. The resulting classification criteria will facilitate rigorous research in SRC. In the meantime, SSc researchers who are designing new studies (either observational or trials) are encouraged to collect these items in their datasets. These will be useful for future external validation of the criteria.

\section{Acknowledgements}

We would like to thank all the participants of the Delphi survey, the participants of the Nominal Group Meeting (Murray Baron, Mary Ellen Csuka, Jeska de vries Bouwstra, Christopher Denton, Tracy Frech, Cybele Ghossein, Sindhu Johnson, Luc Mouthon, Mandana Nikpour, Richard Silver, Virginia Steen) and the content experts (hematology: Mark Blotstein, Stephen Caplan, Nathalie Johnson; cardiology: Vartan Mardigyan, Richard Sheppard; neurology: Robert Altman, Colin Chalk, Rami Massie; ophthalmology: Julius Gomolin) who contributed to this study.

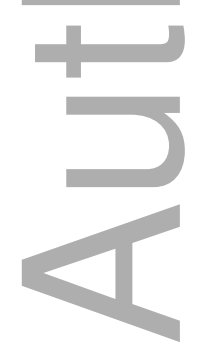

\section{References}

This article is protected by copyright. All rights reserved 
1. Denton CP, Khanna D. Systemic sclerosis. Lancet. 2017;390:1685-99.

2. Helfrich DJ, Banner B, Steen VD, Medsger TA. Normotensive renal failure in systemic sclerosis. Arthritis Rheum. 1989;32:1128-34.

3. Mouthon L, Bérezné A, Bussone G, Noël LH, Villiger PM, Guillevin L. Scleroderma renal crisis: A rare but severe complication of systemic sclerosis. Clin Rev Allergy Immunol. 2011;40:84-91.

4. Steen VD, Syzd A, Johnson JP, Greenberg A, Medsger TA. Kidney disease other than renal crisis in patients with diffuse scleroderma. J Rheumatol. 2005;32:649-55.

5. Caron M, Hudson M, Baron M, Nessim S, Steele R. Longitudinal Study of Renal Function in Systemic Sclerosis. J Rheumatol. 2012;39:1829-34.

6. Nihtyanova SI, Schreiber BE, Ong VH, Rosenberg D, Moinzadeh P, Coghlan JG, et al. Prediction of pulmonary complications and long-term survival in systemic sclerosis. Arthritis Rheumatol. 2014;66:1625-35.

7. Steen VD, Mayes MD, Merkel PA. Assessment of kidney involvement. Clin Exp Rheumatol. 2003;21:S29-S31.

8. Steen VD. Scleroderma and renal crisis. Rheum Dis Clin North Am. 2003;29:315-33.

9. Traub YM, Shapiro AP, Rodnan GP, Medsger TA, McDonald RH, Steen VD, et al. Hypertension and renal failure (scleroderma renal crisis) in progressive systemic sclerosis. Medicine (Baltimore). 1983;62:335-52.

10. Guillevin L, Berezne A, Seror R, Teixeira L, Pourrat J, Mahr A, et al. Scleroderma renal crisis: A retrospective multicentre study on 91 patients and 427 controls. Rheumatology. 2012;51:460-7.

11. Teixeira L, Mouthon L, Mahr A, Berezné A, Agard C, Mehrenberger M, et al. Mortality and risk factors of scleroderma renal crisis: a French retrospective study of 50 patients. Ann Rheum Dis. 2008;67:110-6.

12. Hudson M, Baron M, Tatibouet S, Furst DE, Khanna D, Hummers L, et al. Exposure to ACE inhibitors prior to the onset of scleroderma renal crisis-results from the international scleroderma renal crisis survey. Semin Arthritis Rheum. 2014;43:666-72.

13. Hoa S, Stern EP, Denton CP, Hudson M, Baron M, Frech T, et al. Towards developing criteria for scleroderma renal crisis: A scoping review. Autoimmun Rev. 2017;16:407-15.

14. Barber CEH, Marshall DA, Alvarez N, Mancini GBJ, Lacaille D, Keeling S, et al. Development of Cardiovascular Quality Indicators for Rheumatoid Arthritis: Results from an International 
Expert Panel Using a Novel Online Process. J Rheumatol. 2015;42:1548-55.

15. Schmajuk G, Hoyer BF, Aringer M, Johnson SR, Daikh DI, Dorner T, SLE classification criteria steering committee and the international SLE expert panel of the initiative. Multi-center Delphi Exercise Reveals Important Key Items for Classifying Systemic Lupus Erythematosus. Arthritis Care and Research. 2018; 70:1488-1494.

16. Fitch K, Bernstein SJJ, Aguilar MDD, Burnand B, LaCalle JRR, Lazaro P, et al. The RAND / UCLA Appropriateness Method User's Manual. RAND. 2001. 109 p.

17. Fransen J, Johnson SR, Van Den Hoogen F, Baron M, Allanore Y, Carreira PE, et al. Items for developing revised classification criteria in systemic sclerosis: results of a consensus exercise with the ACR/EULAR working committee for classification criteria in systemic sclerosis. 2012;64:351-7.

18. Johnson SR, Khanna D, Cervera R, Costedoat-Chalumeau N, Gladman, DD, Hahn BH, Hiepe F, Sanchez-Guerrero J, Massarotti E, Boumpas, Costenbader KH, Daikh D, Jayne D, Dörner T, Kamen D, Mosca M, Ramsey-Goldman R, Smolen JS, Wofsy D, Aringer M. Use of Consensus Methodology to Determine Candidate Items for Systemic Lupus Erythematosus Classification Criteria. Journal of Rheumatology. 2018. In press.

19. Kellum J, Lameire N, Aspelin P, Barsoum RS, Burdmann E, Goldstein SL, et al. KDIGO Clinical Practice Guideline for Acute Kidney Injury. Kidney Int Suppl. 2012;2:1-138.

20. Lynch BM, Stern EP, Ong VH, Harber M, Burns A, Denton CP. UK Scleroderma Study Group (UKSSG) Guidelines on the Diagnosis and Management of Scleroderma Renal Crisis. Clin Exp Rheumatol. 2016;34 Suppl 100:106-9

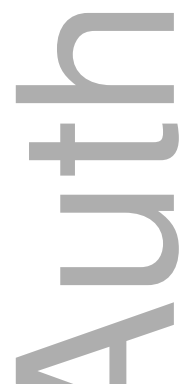

Table 1. Results from Rounds 2 and 3 of the Delphi exercise and consensus achieved after Round 3. 


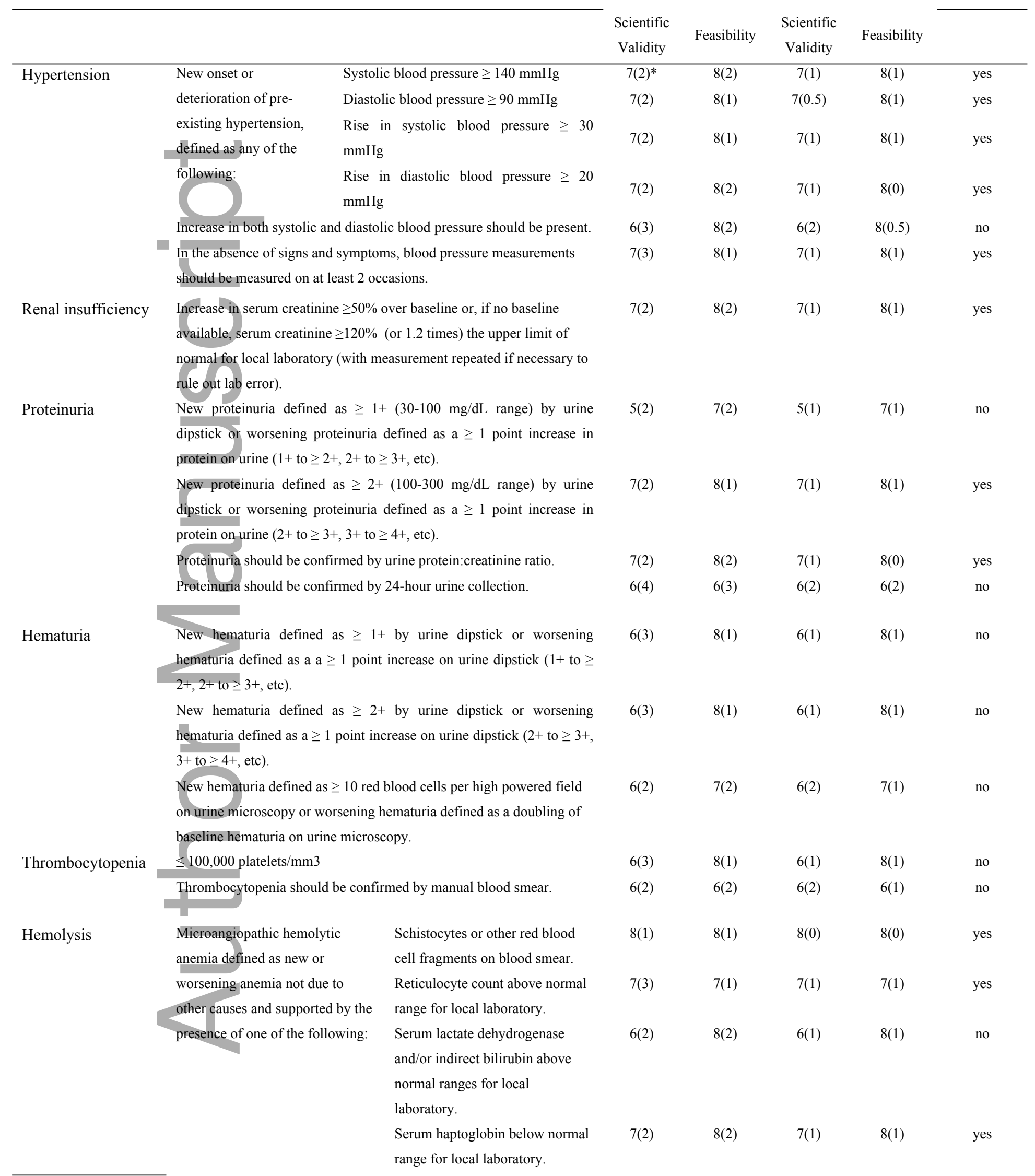


Microangiopathic hemolytic anemia defined as new or worsening anemia not due to other causes and supported by the presence of at least two lab abnormalities (red blood cell fragments, elevated reticulocyte count, elevated serum lactate dehydrogenase/indirect bilirubin, low haptoglobin).

A direct anti-globulin test should be documented to rule out autoimmune hemolytic anemia.
$8(1)$

$8(1)$

$8(0)$

$8(0)$

yes

$7(3)$

$7(2)$

$7(0)$

$7(1)$

yes

* Median values (inter-quartile range)

Table 1. Results from Rounds 2 and 3 of the Delphi exercise and consensus achieved after Round 3 - Continued

\begin{tabular}{|c|c|c|c|c|c|c|}
\hline \multirow[b]{2}{*}{ Criteria Category } & \multirow[b]{2}{*}{ Question } & \multicolumn{2}{|c|}{ Round 2} & \multicolumn{2}{|c|}{ Round 3} & \multirow[b]{2}{*}{ Consensus } \\
\hline & & $\begin{array}{l}\text { Scientific } \\
\text { Validity }\end{array}$ & Feasibility & $\begin{array}{l}\text { Scientific } \\
\text { Validity }\end{array}$ & Feasibility & \\
\hline Encephalopathy & $\begin{array}{l}\text { Encephalopathy defined by the American Academy of Neurology as } \\
\text { follows: 'Any diffuse disease of the brain that alters brain function or } \\
\text { structure. The hallmark of encephalopathy is an altered mental state. } \\
\text { Depending on the type and severity of encephalopathy, common } \\
\text { neurological symptoms are progressive loss of memory and cognitive } \\
\text { ability, subtle personality changes, inability to concentrate, lethargy, } \\
\text { and progressive loss of consciousness. Other neurological symptoms } \\
\text { may include myoclonus (involuntary twitching of a muscle or group of } \\
\text { muscles), nystagmus (rapid, involuntary eye movement), tremor, } \\
\text { muscle atrophy and weakness, dementia, seizures, and loss of ability to } \\
\text { swallow or speak'. }\end{array}$ & $6(3)^{*}$ & $7(2)$ & $6(1)$ & $7(1)$ & no \\
\hline \multirow[t]{2}{*}{ Retinopathy } & Retinopathy typical of malignant hypertension & $7(2)$ & $6(3)$ & $7(1)$ & $6(1)$ & no \\
\hline & $\begin{array}{l}\text { Grade III (flame-shaped hemorrhages and/or "cotton-wool" exudates) } \\
\text { or IV (papilledema) retinopathy, according to Keith-Wagener } \\
\text { classification }\end{array}$ & $7(3)$ & $6(3)$ & $7(1)$ & $6(2)$ & no \\
\hline Hyperreninemia & Elevation of plasma renin activity $\geq 2$ times the upper limit of normal & $7(3)$ & $4(4)$ & $7(1)$ & $5(2)$ & no \\
\hline \multirow[t]{2}{*}{ Cardiac dysfunction } & $\begin{array}{l}\text { Presence of flash pulmonary edema based on all available information } \\
\text { and clinical judgement. }\end{array}$ & $6(2)$ & $7(2)$ & $6(1)$ & $7(0)$ & no \\
\hline & $\begin{array}{l}\text { Presence of symptomatic pericardial effusion based on all available } \\
\text { information and clinical judgement. }\end{array}$ & $6(2)$ & $6(2)$ & $6(1)$ & $6(1)$ & no \\
\hline Abnormal kidney & Findings consistent with scleroderma renal crisis (microangiopathy) & $8(2)$ & $6(4)$ & $8(0)$ & $6(2)$ & no \\
\hline biopsy & Accumulation of mucoid (myxoid) in interlobular arteries & $7(2)$ & $6(4)$ & $7(1)$ & $6(2)$ & no \\
\hline
\end{tabular}


Histopathological findings on kidney biopsy consistent with SRC may

include the following: small vessel (arcuate and interlobular arteries)

changes predominate over glomerular alterations. Early vascular

abnormalities include intimal accumulation of myxoid material,

thrombosis, fibrinoid necrosis, sometimes resulting in cortical necrosis.

Narrowing and obliteration of the vascular lumen lead to glomerular

ischemia. Juxtaglomerular apparatus hyperplasia, while relatively rare

$(10 \%)$, can be observed. Late changes are manifested by intimal

thickening and proliferation (which lead to characteristic vascular

"onion-skin" lesions), glomerulosclerosis and interstitial fibrosis. Since

none of these findings are specific for scleroderma renal crisis, the

pathological diagnosis must be supported by appropriate clinical and

serological data.

* Median values (inter-quartile range)
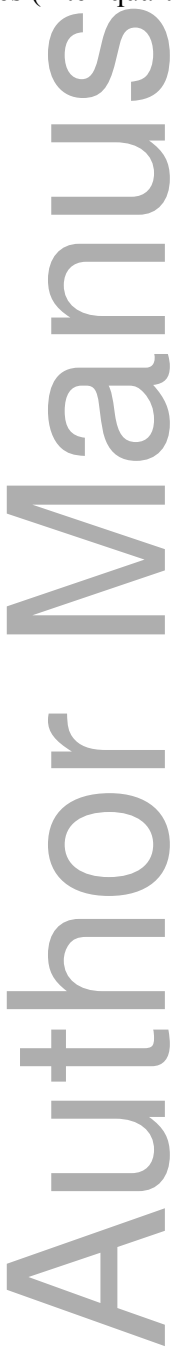
Table 2. Final core set of items to develop classification criteria for SRC

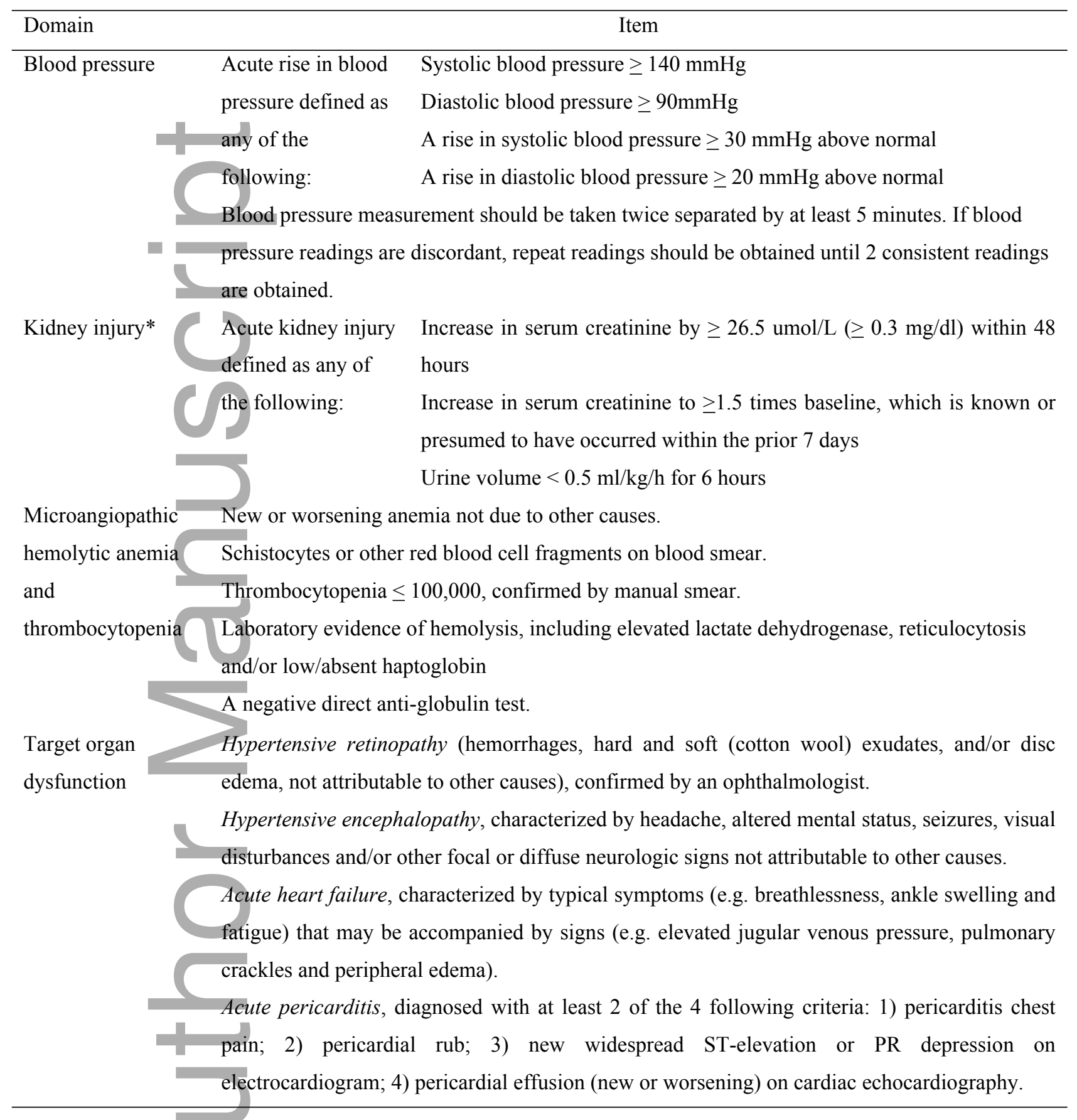




\begin{tabular}{|c|c|}
\hline $\begin{array}{l}\text { Renal } \\
\text { histopathology }\end{array}$ & $\begin{array}{l}\text { Histopathological findings on kidney biopsy consistent with scleroderma renal crisis which } \\
\text { may include the following: small vessel (arcuate and interlobular arteries) changes that } \\
\text { predominate over glomerular alterations. Glomerular changes of thrombotic microangiopathy } \\
\text { may be present, with acute changes including fibrin thrombi and endothelial swelling, red } \\
\text { blood cell fragments and mesangiolysis, and chronic changes including double contours of the } \\
\text { glomerular basement membrane. Nonspecific ischemic changes with corrugation of the } \\
\text { glomerular basement membrane, and even segmental or global sclerosis of glomeruli may } \\
\text { occur. Early vascular abnormalities include intimal accumulation of myxoid material, } \\
\text { thrombosis, fibrinoid necrosis, fragmented red blood cells, sometimes resulting in cortical } \\
\text { necrosis. Narrowing and obliteration of the vascular lumen lead to glomerular ischemia. } \\
\text { Juxtaglomerular apparatus hyperplasia, while relatively rare (10\%), can be observed. Late } \\
\text { changes are manifested by intimal thickening and proliferation (which lead to characteristic } \\
\text { vascular "onion-skin" lesions), glomerulosclerosis and interstitial fibrosis. Nonspecific tubular } \\
\text { changes may also occur, including acute tubular injury in the early stage of injury, and later } \\
\text { interstitial fibrosis and tubular atrophy. Since none of these findings are specific for SRC, the } \\
\text { pathological diagnosis must be supported by appropriate clinical and serological data. }\end{array}$ \\
\hline
\end{tabular}

*This is the definition of acute kidney injury from the Kidney Disease Improving Global Outcomes (KDIGO) guidelines (19)

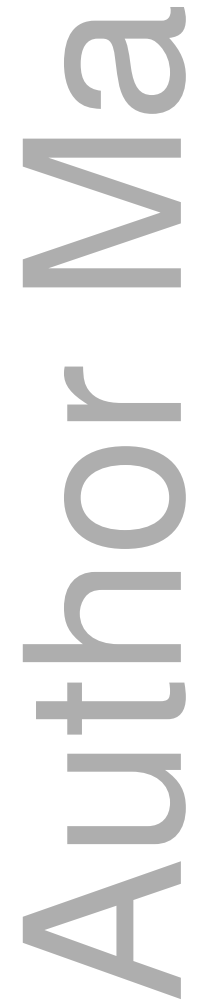




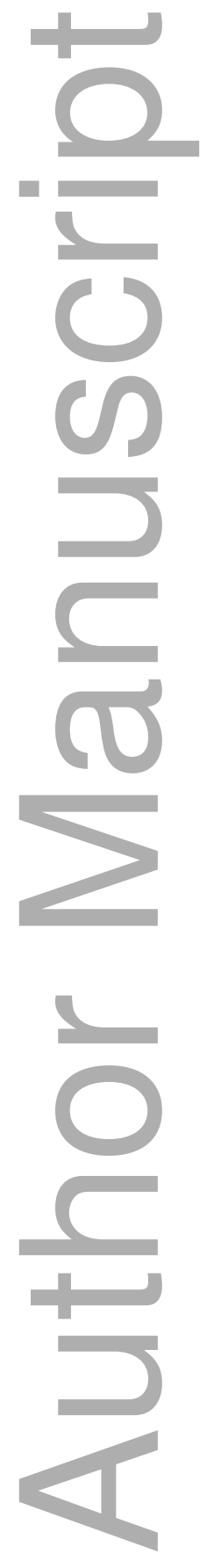

This article is protected by copyright. All rights reserved 